\title{
The use, appropriateness and outcomes of outpatient parenteral antimicrobial therapy
}

\author{
Kate A Hodgson, ${ }^{1}$ Julie Huynh, ${ }^{1}$ Laila F Ibrahim, ${ }^{1}$ Bronwyn Sacks, ${ }^{1}$ \\ Daniel Golshevsky, ${ }^{1}$ Michael Layley, ${ }^{1}$ Mark Spagnolo, ${ }^{1}$ Chin-Mae Raymundo, \\ Penelope A Bryant 1,2,3,4
}

1RCH@Home Department, The Royal Children's Hospital Melbourne, Parkville, Victoria, Australia

${ }^{2}$ Infectious Diseases Unit, Department of General Medicine, The Royal Children's Hospital Melbourne, Parkville, Victoria, Australia

${ }^{3}$ Clinical Paediatrics Group, Murdoch Children's Research Institute, The Royal Children's Hospital Melbourne, Parkville, Victoria, Australia

${ }^{4}$ Department of Paediatrics, University of Melbourne, The Royal Children's Hospital Melbourne, Parkville, Victoria, Australia

\section{Correspondence to} Dr Penelope A Bryant, The Royal Children's Hospital Melbourne, 50 Flemington Road, Parkville, VIC 3052,

Australia.penelope.bryant@ rch.org.au

Received 10 September 2015 Revised 19 April 2016 Accepted 20 April 2016 Published Online First 10 May 2016

\section{SLinked}

- http://dx.doi.org/10.1136/ archdischild-2016-311099

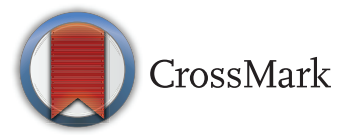

To cite: Hodgson $\mathrm{KA}$, Huynh J, Ibrahim LF, et al. Arch Dis Child

2016:101:886-893.

\section{ABSTRACT}

Objective Outpatient parenteral antimicrobial therapy (OPAT) is increasingly used to treat children at home, but studies in children are scarce. We aimed to describe the use, appropriateness and outcomes of OPAT in children.

Design This was a 12-month prospective observational study.

Setting The hospital-in-the-home programme of The

Royal Children's Hospital Melbourne.

Patients All patients receiving OPAT.

Interventions Data were collected including demographics, diagnosis, type of venous access and antibiotic choice.

Main outcome measures Length of stay, adverse events, readmission rate and appropriateness of antibiotic use.

Results 228 patients received OPAT in 251 episodes. The median age was 7.4 years (range 1 week to 21 years), with 22 patients (10\%) under 1 year. The most frequent diagnoses were exacerbation of cystic fibrosis $(17 \%)$, urinary tract infection $(12 \%)$ and cellulitis $(9 \%)$. Most patients were transferred from the ward, but $18 \%$ were transferred directly from the emergency department, the majority with skin and soft-tissue infection $(66 \%)$. Venous access was most commonly peripherally inserted central catheter $(29 \%)$ and peripheral cannula (29\%). 309 parenteral antibiotics were prescribed, most frequently ceftriaxone $(28 \%)$ and gentamicin (19\%). The majority of antibiotics (72\%) were prescribed appropriately. However, $6 \%$ were deemed an inappropriate choice for the indication and $26 \%$ had inappropriate dose or duration. The incidence of central line-associated bloodstream infections was $0.9 \%$. The unplanned readmission rate was $4 \%$, with low rates of OPAT-related adverse events. Three children $(1 \%)$ had an inadequate clinical response.

Conclusions OPAT is a safe and effective way of providing antibiotics to children. Despite high rates of appropriate antibiotic use, improvements can still be made.

\section{BACKGROUND}

Outpatient parenteral antimicrobial therapy (OPAT) is increasingly used for the systemic treatment of serious infections in the home environment. Compared with hospital admission, there are a number of potential benefits for the patient of being at home, including improved psychological outcomes, less disruption to family life and reduced hospital-acquired infections ${ }^{12}$ There are also benefits to the healthcare system, including improved

\section{What is already known on this topic?}

- Outpatient parenteral antimicrobial therapy (OPAT) is increasingly being used for the treatment of infections in the home environment.

- OPAT is particularly desirable for children to minimise the negative psychosocial impact of hospitalisation.

- OPAT presents unique issues in children.

\section{What this study adds?}

- This is the largest single centre study of intravenous antibiotics delivered at home.

- There was a high rate of peripheral cannula use and low rates of venous access and other OPAT-related problems.

- Lack of appropriateness was most commonly related to drug dosing and excessive durations.

patient flow and greater cost-effectiveness for the same management. ${ }^{3}$ With changing models of care and greater financial pressure on hospitals, the impetus for home-based care is likely to increase. OPAT can be delivered in a number of ways: by patients visiting ambulatory units at hospital, by patients or parents being taught how to administer intravenous antibiotics and by nurses visiting the home to administer antibiotics, for example, under a hospital-in-the-home (HITH) programme. Australian hospitals are funded through a combination of federal and state government funding, providing universal public healthcare and OPAT is generally delivered via hospital-based programmes.

HITH programmes provide daily acute medical care within the home, for services that would otherwise need to be delivered in hospital (eg, intravenous antibiotics, wound care, physiotherapy). Programmes vary, but the core model involves nursing staff, usually based at a hospital, visiting patients at home to provide medical interventions. In adults, studies show equivalent outcomes to inpatient care, reduced re-presentation rates and higher patient and carer satisfaction rates. ${ }^{3-5}$ OPAT is one of the interventions that can be delivered by an HITH programme, and in adults it has been shown to improve physical, social and emotional quality-of-life parameters compared with hospital- 
based treatment. ${ }^{3}$ However, there are potential risks such as adverse events at home and suboptimal decision-making regarding antibiotics.

OPAT presents unique issues in children. The Infectious Diseases Society of America guidelines for OPAT state that "home care in children requires standards the same as, if not higher than, those for adults". ${ }^{6}$ UK and Canadian guidelines have also been published recently for paediatric OPAT. ${ }^{1}{ }^{7}$ All three guidelines highlight aspects specific to children including dedicated paediatric nursing skills, central venous access and complications of infections and treatment that differ from adults. Socially, children also need to be considered in the context of their family and school. There are significantly fewer studies on OPAT in children than in adults. ${ }^{78}$ While in theory advantageous, a recent retrospective review of OPAT at one centre showed higher than expected rates of complications and treatment failures. ${ }^{9}$

In this prospective study, we aimed to describe the use and outcomes of OPAT delivered via the largest paediatric HITH programme in Australasia. For the first time, we also aimed to assess the appropriateness of antibiotic use in OPAT in children.

\section{METHODS}

Design

This was a 12-month prospective study of OPAT in children.

\section{Setting}

The Royal Children's Hospital (RCH) Melbourne HITH programme, from 1 August 2012 to 31 July 2013. The RCH has 334 beds and the HITH programme operates as a virtual ward of 32 beds, that is, 32 patients at any time.

\section{Participants}

All patients receiving parenteral antibiotics under HITH were included.

\section{Data collection}

Demographic data (age, sex, referring unit) and information about the treatment of the infection (diagnosis, microbiology results if relevant to the OPAT course, intravenous access device, antibiotic) were collected. Outcome data were length of stay in hospital and under HITH, readmissions and adverse events. Adverse events collected were line-related complications including central line-associated bloodstream infections (CLABSI) and antibiotic complications necessitating a change or cessation of antibiotic. The appropriateness of antibiotic prescribing was assessed by two physicians in paediatric infectious diseases and general paediatrics, based on (1) the decision to use an antibiotic; (2) the choice of antibiotic, including the context of its use for OPAT; and (3) its application: dose, frequency, route and duration. Differences were resolved by discussion. Choice was deemed 'too broad' if it was unnecessarily broad for the cultured organism or indication, or that there was unnecessary divergence from hospital antibiotic guidelines unless it was the only antibiotic that could be used for OPAT (ie, once or twice daily or in a $24 \mathrm{~h}$ infuser), and 'too narrow' if the antibiotic did not cover the organism isolated or indication. Dose was deemed inappropriate if it was outside a $10 \%$ margin either side of the recommended dose range in the $\mathrm{RCH}$ drug dosing guideline without a reason. Duration was deemed too long if there had been no switch to oral antibiotics despite clear clinical improvement and decreased inflammatory markers and it was not a condition necessitating solely intravenous treatment. Accuracy of documentation and drug monitoring were also assessed. The cost of OPAT per day was calculated to include (1) salaries of staff (nursing, allied health, medical, administrative), (2) operational costs (vehicle fleet, insurance, business costs and overheads, information technology - phones, computers, software licensing, etc) and (3) patient-related costs (clinical supplies, the cost of outsourcing care for children outside of the service catchment area).

\section{Treatment}

Care was provided as per the referring unit's request, with the referring unit deciding upon antibiotic choice and duration. All antibiotics were administered by trained nurses, not parents. Central venous catheter (CVC) care was consistent with hospital guidelines: no-touch sterile technique, dressings changed every seven days and inspection daily to identify insertion-site infection. Heparin locks were used for CVCs that were not continuously accessed. Antimicrobial agents were administered either through $24 \mathrm{~h}$ elastomeric infusers as a short push or using pumps over a defined time frame. Visits by HITH nurses occurred daily or twice daily depending on the antibiotic prescribed.

\section{Analysis}

Statistical tests for significance were used where appropriate: $\chi^{2}$ tests for categorical data and $t$ tests for continuous data.

\section{RESULTS}

\section{Demographics and clinical characteristics}

There were 228 individuals admitted for 251 separate patient episodes to HITH for OPAT over 12 months. Of these, 17 (7\%) were treated on two occasions and $3(1 \%)$ were treated three times.

The median age was 7.4 years (range 1 week to 21.9 years) with 22 patients (10\%) under the age of 1 year. One hundred patients $(44 \%)$ were female. While most patients were referred from inpatient wards, $42(18 \%)$ were referred directly from the emergency department (ED). The units from which the majority of referrals were received were general medicine (55 patients, 24\%), haematology/oncology (38 patients, 17\%), respiratory (29 patients, 13\%) and orthopaedics (25 patients, 11\%). Patients were transferred to HITH a median of 4 days after hospital admission (range $0-83$ days).

The most frequent diagnoses for which patients received OPAT were exacerbation of cystic fibrosis and urinary tract infection (UTI) (table 1). Of the 42 admitted directly from the ED, the majority were for skin and soft-tissue infection (25 patients, $60 \%)$ and UTI (14 patients, 33\%). The remaining few were pneumonia worsening despite oral antibiotics, CLABSI and septic arthritis. The most common types of venous access were peripherally inserted central catheter (PICC, 71 patients, 29\%) and peripheral cannula $(71,29 \%)$, followed by tunnelled/nontunnelled CVC (40,16\%), portacath $(35,14 \%)$, midline catheter $(24,10 \%)$ or no access (6 intramuscular, $2 \%)$, with 4 not recorded. A midline catheter is a longer peripheral line inserted via a cubital fossa vein and advanced with the tip ending proximal to the axillary vein.

\section{Microbiology}

In $150(60 \%)$ patient episodes, bacteria were isolated, with 180 positive bacterial cultures (table 2). There were additionally 45 fungi and 4 viruses isolated, although not treated during the OPAT episode. In skin and soft-tissue infections and musculoskeletal infections, the most commonly isolated bacteria was Staphylococcus aureus, and in UTI the most common 
Table 1 Number of patient episodes of outpatient parenteral antimicrobial therapy for different infections

\begin{tabular}{|c|c|c|c|c|c|}
\hline $\begin{array}{l}\text { Type of } \\
\text { infection }\end{array}$ & $\begin{array}{l}\text { No. } \\
n=251\end{array}$ & $\%$ & Diagnosis & No. & $\%$ \\
\hline \multirow[t]{9}{*}{$\begin{array}{l}\text { Skin and soft } \\
\text { tissue }\end{array}$} & 58 & 23.1 & $\begin{array}{l}\text { Cellulitis-limbs/trunk/ } \\
\text { face }\end{array}$ & 23 & 9.2 \\
\hline & & & Lymphadenitis & 6 & 2.4 \\
\hline & & & Skin abscess & 4 & 1.6 \\
\hline & & & CVC site infection & 4 & 1.6 \\
\hline & & & $\begin{array}{l}\text { Deep surgical-site } \\
\text { infection }\end{array}$ & 4 & 1.6 \\
\hline & & & $\begin{array}{l}\text { Superficial surgical-site } \\
\text { infection }\end{array}$ & 3 & 1.2 \\
\hline & & & Periorbital cellulitis & 3 & 1.2 \\
\hline & & & Orbital cellulitis & 2 & 0.8 \\
\hline & & & $\begin{array}{l}\text { Skin and soft tissue- } \\
\text { other }\end{array}$ & 9 & 3.6 \\
\hline \multirow[t]{4}{*}{ Respiratory } & 56 & 22.3 & $\begin{array}{l}\text { Cystic fibrosis } \\
\text { exacerbation }\end{array}$ & 43 & 17.1 \\
\hline & & & $\begin{array}{l}\text { Lower respiratory tract } \\
\text { infection }\end{array}$ & 7 & 2.8 \\
\hline & & & $\begin{array}{l}\text { Non-CF bronchiectasis } \\
\text { exacerbation }\end{array}$ & 3 & 1.2 \\
\hline & & & Pharyngitis/tonsillitis & 3 & 1.2 \\
\hline \multirow[t]{8}{*}{ Bloodstream* } & 44 & 17.5 & CLABSI & 29 & 11.6 \\
\hline & & & Gram-positive bacteria & 18 & 7.2 \\
\hline & & & Gram-negative bacteria & 10 & 4.0 \\
\hline & & & Mycobacteria & 1 & 0.4 \\
\hline & & & Bacteraemia & 15 & 6.0 \\
\hline & & & Gram-positive bacteria & 2 & 0.8 \\
\hline & & & Gram-negative bacteria & 7 & 2.8 \\
\hline & & & Suspected & 6 & 2.4 \\
\hline \multirow[t]{5}{*}{ Musculoskeletal } & 39 & 15.5 & Acute osteomyelitis & 20 & 8.0 \\
\hline & & & Septic arthritis & 7 & 2.8 \\
\hline & & & Chronic osteomyelitis & 6 & 2.4 \\
\hline & & & Discitis & 4 & 1.6 \\
\hline & & & Pyomyositis & 2 & 0.8 \\
\hline Genitourinary & 30 & 12.0 & Urinary tract infection & 30 & 12.0 \\
\hline \multirow[t]{2}{*}{ CNS } & 21 & 8.4 & Meningitis & 19 & 7.6 \\
\hline & & & Cerebral abscess & 2 & 0.8 \\
\hline Cardiac & 2 & 0.8 & Endocarditis & 2 & 0.8 \\
\hline Abdominopelvic & 1 & 0.4 & Ascending cholangitis & 1 & 0.4 \\
\hline
\end{tabular}

*Twenty-six of the bloodstream infections were in immunocompromised patients.

CLABSI, central line-associated bloodstream infection; CVC, central venous catheter.

was Escherichia coli. In de novo bacteraemia, the most common was Salmonella typhi, while in CLABSI coagulase negative staphylococci were most common. Children with cystic fibrosis commonly had organisms isolated from their sputum, for example, Haemophilus spp., Stenotrophomonas maltophilia and Candida spp., but these were not always followed specifically with antibiotic choice, as per current recommendations for the management of cystic fibrosis.

\section{Antibiotic prescribing and appropriateness}

In total, 309 parenteral antibiotics were prescribed: 304 intravenous, 3 intramuscular and 2 intravenous followed by intramuscular. Simultaneously, 57 patients also had an oral antibiotic and 1 an intranasal antibiotic prescribed. During their OPAT course, 196 patients received one parenteral antibiotic, 55 patients (21\%) received two antibiotics and 1 patient received three antibiotics. The most frequently administered antibiotics were ceftriaxone (87 prescriptions, 28\%) and gentamicin (59 prescriptions, 19\%) (figure 1).

All prescriptions are written on a drug chart and an HITH care plan documenting the reason for treatment. The reason was documented on the HITH care plan for 267/269 (99\%) prescriptions, but the antibiotic name and dose were both correctly documented in only 194/226 (86\%).

The majority of antibiotic courses (222 prescriptions, 72\%) were prescribed fully appropriately. However, 6\% were deemed an inappropriate choice for the indication-these were all 'too broad' and there were no instances where the antibiotic was 'too narrow'. In addition, 26\% were inappropriate dose, route or duration (table 3 ). The majority of this was incorrect dose (19\%), although there were also a number that were prescribed for too long with no indication (8\%). There were 78 aminoglycoside prescriptions, of which 65 should have had at least one level done while receiving OPAT. Of these, 58 (89\%) had a level taken, with 19 high. Of these, eight were spuriously high $(>10 \mathrm{mg} / \mathrm{L})$ and had been taken from CVCs. In response to the remaining high levels, there was no clear documentation of appropriate dose reduction before the next dose was administered.

\section{Outcomes}

The median length on OPAT was 7 days (range 1-190 days), although this varied between conditions (table 4). The shortest lengths of OPAT with a median of 1-2 days were for skin abscess, cellulitis, community-acquired pneumonia and UTI. The longest lengths of stay with a median over 21 days were for ascending cholangitis, pyomyositis, chronic osteomyelitis, discitis and cerebral abscess. In total, over 12 months this represented 3084 days where patients were treated with OPAT rather than as inpatients.

OPAT-related adverse events were all related to vascular access. There were three CLABSI that occurred while receiving OPAT, one each in a portacath, a tunnelled CVC and a PICC. With one culture-confirmed Pseudomonas CLABSI and two culture-negative septic episodes on intravenous flush, this resulted in an incidence of $0.9 \%$ or $0.54 / 1000$ line days. There were 11 other line complications: 1 tunnelled CVC, 2 PICCs, 2 midline catheters and 2 peripheral cannulae that blocked; 1 tunnelled CVC, 1 PICC and 1 peripheral cannula that dislodged and 1 midline that developed paresthesia at the insertion site- 6 lines were replaced, 5 were not. This resulted in an overall access complication rate where it was recorded of $11 \%(14 /$ 133): CVC/portacath 4/45 (9\%), PICC 4/46 (9\%), peripheral cannulae $3 / 26(11 \%)$ and midline catheters $3 / 7$ (43\%). There were no antibiotic adverse events necessitating change or cessation of antibiotic or hospital readmission.

There were 11 unplanned readmissions in nine patients, a rate of $4 \%$ (table 5). Three were related to inadequate clinical improvement of the infection being treated via OPAT, four had line complications; four were coincidental and unrelated to the infection or OPAT, for example, concurrent viral illness (table 6). The majority of children were admitted for observation before returning to OPAT with no changes. Overall, only 1 of 251 OPAT episodes was abandoned due to persistently positive blood cultures (table 6, patient 3). All others had resolution of infection by the end of the OPAT course or improvement sufficient to switch to oral antibiotics to complete the course.

\section{Cost}

At our hospital, the reduction in cost to care for a patient at home receiving OPAT compared with the average cost of care in a hospital bed for a medical patient is AU\$590/day. This includes medical and nursing care, operational costs such as the use of cars and patient consumables. As there were 3084 days where OPAT replaced inpatient care, this represents an estimated cost saving of AU\$1.82 million in 1 year. 
Table 2 Bacterial culture results associated with different diagnoses from 251 episodes of paediatric outpatient parenteral antimicrobial therapy

\begin{tabular}{|c|c|c|c|c|}
\hline \multirow{2}{*}{$\begin{array}{l}\text { Type of infection } \\
\text { No. culture positive/total (\%) } \\
\text { Culture positive samples }\end{array}$} & \multicolumn{4}{|l|}{ Bacteria isolated } \\
\hline & Gram positive & No. & Gram negative & No. \\
\hline $\begin{array}{l}\text { Skin and soft tissue } \\
27 / 58(46.6 \%) \\
\text { Skin swab } 15 \\
\text { Pus } 12\end{array}$ & $\begin{array}{l}\text { Staphylococcus aureus (MRSA 3) } \\
\text { Streptococcus pyogenes } \\
\text { CoNS } \\
\text { Streptococcus spp. other } \\
\text { Propionibacterium acnes } \\
\text { Gram-positive cocci }\end{array}$ & $\begin{array}{r}17 \\
5 \\
3 \\
2 \\
1 \\
1\end{array}$ & Pseudomonas aeruginosa & 3 \\
\hline $\begin{array}{l}\text { Respiratory } \\
37 / 56(66.1 \%) \\
\quad \text { Sputum } 36 \\
\quad \text { Throat swab } 1\end{array}$ & $\begin{array}{l}\text { S. aureus (MRSA 0) } \\
\text { Streptococcus pneumoniae } \\
\text { Nocardia spp. } \\
\text { CoNS }\end{array}$ & $\begin{array}{l}7 \\
1 \\
1 \\
1\end{array}$ & $\begin{array}{l}\text { Haemophilus parainfluenzae } \\
\text { Stenotrophomonas maltophilia } \\
\text { Haemophilus influenzae non-typeable } \\
\text { P. aeruginosa } \\
\text { Serratia marcescens } \\
\text { Escherichia coli } \\
\text { Brevundimonas spp. } \\
\text { Mycobacterium abscessus }\end{array}$ & $\begin{array}{r}10 \\
8 \\
7 \\
2 \\
1 \\
1 \\
1 \\
1\end{array}$ \\
\hline $\begin{array}{l}\text { Bloodstream } \\
38 / 44(86.3) \\
\quad \text { Peripheral blood } 9 \\
\quad \text { CVC blood } 29\end{array}$ & $\begin{array}{l}\text { CoNS } \\
\text { S. aureus (MRSA 1) } \\
\text { Bacillus cereus } \\
\text { Streptococcus agalactiae } \\
\text { S. pneumoniae } \\
\text { Streptococcus viridans } \\
\text { Streptococcus mitis } \\
\text { Enterococcus faecalis } \\
\text { Leuconostoc spp. } \\
\text { Micrococcus spp. }\end{array}$ & $\begin{array}{l}9 \\
4 \\
2 \\
1 \\
1 \\
1 \\
1 \\
1 \\
1 \\
1\end{array}$ & $\begin{array}{l}\text { P. aeruginosa } \\
\text { Salmonella typhi } \\
\text { Klebsiella spp. } \\
\text { E. coli } \\
\text { Salmonella spp. other } \\
\text { Enterobacter cloacae } \\
\text { Citrobacter freundii } \\
\text { Gram-negative bacillus } \\
\text { Roseomonas spp. } \\
\text { Mycobacterium chelonae }\end{array}$ & $\begin{array}{l}4 \\
4 \\
3 \\
2 \\
2 \\
1 \\
1 \\
1 \\
1 \\
1\end{array}$ \\
\hline $\begin{array}{l}\text { Musculoskeletal } \\
17 / 39(43.6 \%) \\
\quad \text { Bone/joint aspirate } 18 \\
\text { Blood } 3\end{array}$ & $\begin{array}{l}\text { S. aureus } \\
\text { B. cereus } \\
\text { S. pneumoniae } \\
\text { S. intermedius }\end{array}$ & $\begin{array}{r}13 \\
1 \\
1 \\
1\end{array}$ & $\begin{array}{l}\text { E. coli } \\
\text { Citrobacter spp. } \\
\text { Acinetobacter baumannii }\end{array}$ & $\begin{array}{l}2 \\
2 \\
1\end{array}$ \\
\hline $\begin{array}{l}\text { Genitourinary } \\
22 / 30(73.3) \\
\quad \text { Urine } 22\end{array}$ & & & $\begin{array}{l}\text { E. coli } \\
\text { Klebsiella spp. } \\
\text { Enterobacter cloacae } \\
\text { P. aeruginosa }\end{array}$ & $\begin{array}{r}14 \\
3 \\
3 \\
3\end{array}$ \\
\hline $\begin{array}{l}\text { CNS } \\
8 / 21(38.1) \\
\quad \text { CSF } 5, \text { urine } 1 \\
\text { Pus } 2\end{array}$ & $\begin{array}{l}\text { S. pneumoniae } \\
\text { S. agalactiae } \\
\text { S. pyogenes } \\
\text { S. aureus (MRSA 1) }\end{array}$ & $\begin{array}{l}1 \\
1 \\
1 \\
1\end{array}$ & $\begin{array}{l}\text { E. coli } \\
\text { Neisseria sicca } \\
\text { Salmonella spp. }\end{array}$ & $\begin{array}{l}2 \\
1 \\
1\end{array}$ \\
\hline $\begin{array}{l}\text { Cardiac } \\
1 / 2(50.0) \\
\quad \text { Blood } 1\end{array}$ & S. aureus & 1 & & \\
\hline
\end{tabular}

CoNS, coagulase negative staphylococcus; CVC, central venous catheter.

\section{DISCUSSION}

The RCH HITH programme, which provides the OPAT service, is the largest paediatric programme in Australasia, with 1899 separate patient episodes during the study period. Although OPAT represents a relatively small proportion of overall numbers $(13 \%)$, if single day planned episodes are excluded, OPAT is the most frequent treatment, 251/809 (31\%). At the time of this study, it had a part-time medical consultant and a medical registrar, nursing and physiotherapy staff, all paediatrictrained and administrative staff. There was no dedicated pharmacist. Referrals are made via the HITH senior nursing staff, who assess the patient to determine suitability for OPAT, with the HITH medical staff involved in more complex patients and those referred from the ED. Patients remain under their referring team's care with all decisions regarding treatment, review and monitoring made by that team. CVC care and therapeutic drug-level monitoring is done as per hospital guidelines by the HITH staff, with results fed back to the treating team. At the time of this study, the Infectious Diseases team was involved with patients receiving OPAT only at the referring team's request. With 309 antibiotic courses in 251 patient episodes, this study is the largest prospective study in children, including very young infants, to date showing the efficacy and safety of OPAT.

OPAT is particularly desirable for children to minimise the negative psychosocial impact of hospitalisation ${ }^{10}$ and disruption to family life. ${ }^{8}$ Given the choice, the majority of parents prefer to be at home rather than have their child in hospital. ${ }^{11}$ Depending on clinical response, children can still attend school or nursery, limiting educational interruptions, and parents can therefore attend work. This is usual practice and is considered safe, with an occlusive dressing in place over the venous access and parents/teachers receiving instructions in the event of dislodgement or other issue. In addition, hospital-acquired infections are an increasing issue in children and home-based care reduces these. International recommendations for the safety of OPAT in children emphasise the necessity for nursing staff experienced in paediatric assessment and specific vascular access considerations. ${ }^{1}$ At the $\mathrm{RCH}$, the HITH nurses are all paediatric-trained, although patients who live beyond the catchment radius have care outsourced to local services, which may have predominantly adult-trained nurses. Although our data did 


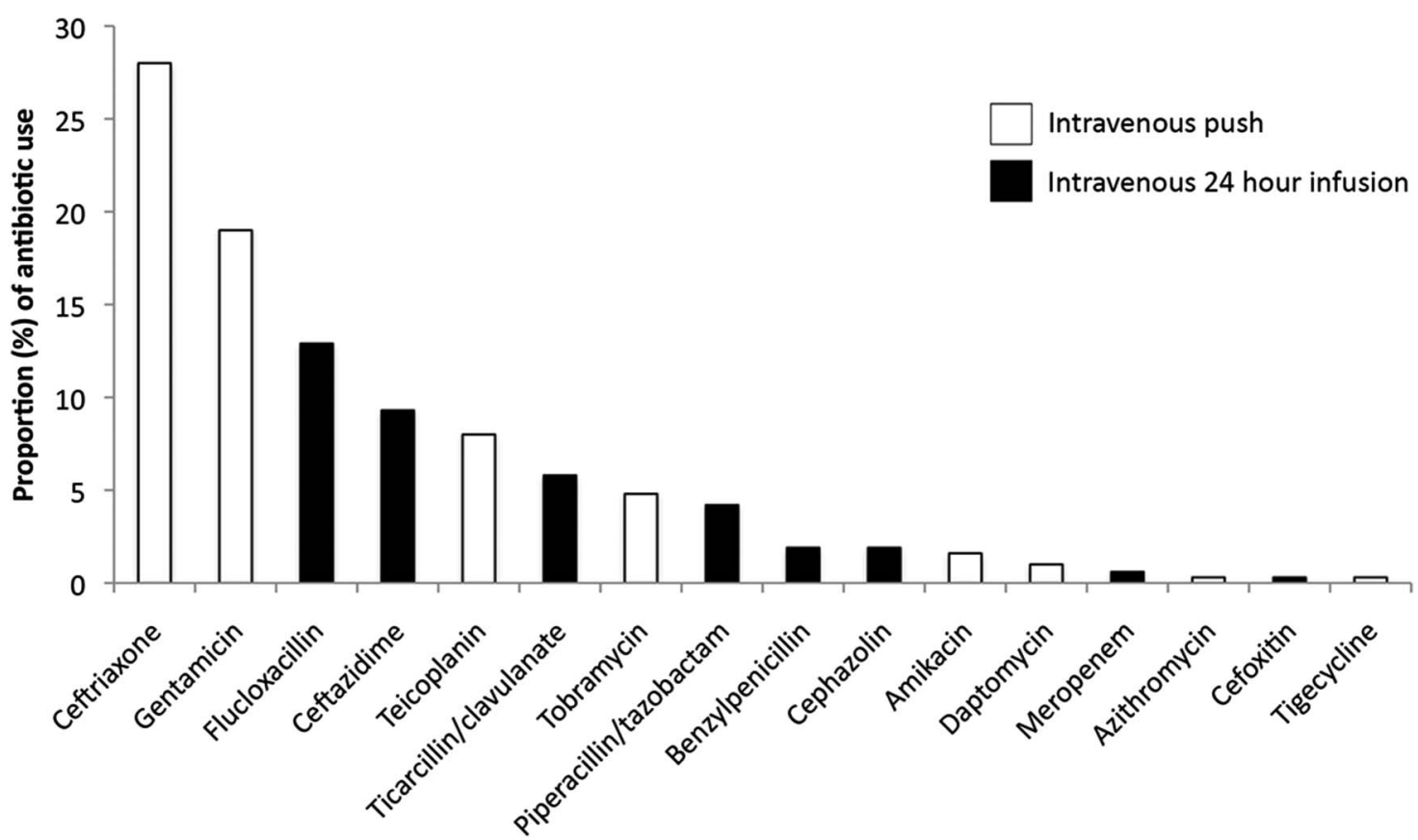

Figure 1 Proportion of overall use for each antibiotic during 251 episodes of paediatric outpatient parenteral antimicrobial therapy.

not differentiate safety outcomes between paediatric and adulttrained nurses, ensuring skills are matched to the patient group is important in maintaining the integrity and safety of homecare services for children.

Regarding vascular access, the differences between adults and children are the need in young patients for a general anaesthetic when inserting a CVC and the small gauge making paediatric lines more susceptible to blockage. However, our study had a high proportion of children who were managed with peripheral cannulae, and overall complication rates were relatively low in our study at $11 \%$. Previous studies on the safety of central catheters for OPAT in children have found complication rates of 29-33\%. ${ }^{112}$ Our overall complication rate for PICC, CVC and portacaths combined was $9 \%$, and it is not clear why this rate is so much lower. It may reflect different selection criteria for patients related to our high rate of peripheral cannula use, strong hospital education from the Infection Control team about CVC care or possibly under-reporting of complications, for example, if a peripheral cannula blocked at the time OPAT

Table 3 Appropriateness of outpatient parenteral antimicrobial therapy (OPAT) prescriptions from 251 episodes of paediatric OPAT

\begin{tabular}{lcc}
\hline Appropriateness & No. of prescriptions & $\%$ \\
\hline Appropriate & 222 & 72 \\
Inappropriate decision & 0 & 0 \\
Inappropriate choice & 20 & 6 \\
Too broad & 20 & 6 \\
Too narrow & 0 & 0 \\
Inappropriate application & 77 & 26 \\
Wrong dose & 58 & 19 \\
$\quad$ Too high & 8 & 3 \\
$\quad$ Too low & 50 & 16 \\
Too long & 25 & 8 \\
Wrong interval & 2 & 0.6 \\
Wrong route & 0 & 0 \\
\hline
\end{tabular}

was due to cease, this complication may not have been recorded. Adverse drug reactions occurred in 29\% of OPAT courses in one case series, prompting early discontinuation of antibiotics in $24 \% .^{13}$ There were no antibiotic allergic reactions in our cohort, but neither was there discontinuation of antibiotics due to any other side effects. While some patients had monitoring for drug effects (eg, liver function tests while receiving flucloxacillin), this was at the discretion of the treating teams and not done reliably in all patients, so this was identified as an area for increased stewardship. In addition, milder side effects such as diarrhoea were not collected, so these numbers are likely to be an underestimate of overall side effects. Despite this, we have shown the safety of OPAT in children: adverse events occurred uncommonly and the readmission rates were low.

Conditions that have previously been shown to be safely and effectively treated with OPAT are usually stable and require prolonged antibiotic courses such as cystic fibrosis exacerbations and osteoarticular infections. ${ }^{14}$ 15 Even these well-established OPAT conditions have in some studies been shown to have poorer outcomes compared with inpatient care. ${ }^{16}$ However, closer analysis of these studies reveals that inpatient and OPAT care were not equivalent (eg, less physiotherapy when receiving OPAT), inpatients were sicker and therefore had greater room for improvement in lung function tests, or that some outcomes were worse but not all. There are no randomised studies of OPAT in cystic fibrosis and the patient group and service type need to be taken into account when trying to generalise results. While cystic fibrosis exacerbations and osteoarticular infections comprised a large proportion of our cohort, there were also a number of infections that could be considered less clinically stable (bloodstream infections 18\%) and requiring much shorter antibiotic courses (UTI, cellulitis), suggesting a willingness to use OPAT for newer indications. ${ }^{11}$ The microbiological data provided in this study reassure that a wide variety of organisms are treatable via OPAT and are as expected for the infections treated.

Referral to OPAT directly from the ED was a new pathway in this 12-month period. Unlike the majority of OPAT episodes, 
Table 4 Median length of admission and outpatient parenteral antimicrobial therapy (OPAT) according to diagnosis in 251 episodes of paediatric OPAT

\begin{tabular}{|c|c|c|c|c|}
\hline Type of infection & No. & Diagnosis & $\begin{array}{l}\text { Median length of hospital stay } \\
\text { prior to OPAT, days (range) }\end{array}$ & $\begin{array}{l}\text { Median length of OPAT, } \\
\text { days (range) }\end{array}$ \\
\hline Skin and soft tissue & 58 & $\begin{array}{l}\text { Cellulitis } \\
\text { Lymphadenitis } \\
\text { Skin abscess } \\
\text { CVC site infection } \\
\text { Deep surgical-site infection } \\
\text { Superficial surgical-site infection } \\
\text { Periorbital cellulitis } \\
\text { Orbital cellulitis } \\
\text { Skin and soft tissue-other }\end{array}$ & $\begin{aligned} 1 & (1-8) \\
2 & (1-25) \\
3 & (0-5) \\
8 & (1-13) \\
27 & (14-49) \\
14 & (7-31) \\
2 & (1-3) \\
5 & (2-7) \\
3 & (1-9)\end{aligned}$ & $\begin{aligned} & (1-7) \\
3 & (2-37) \\
6 & (3-23) \\
7 & (6-7) \\
42 & (25-58) \\
10 & (8-23) \\
2 & (1-4) \\
12 & (1-24) \\
8 & (2-41)\end{aligned}$ \\
\hline Respiratory & 56 & $\begin{array}{l}\text { Cystic fibrosis exacerbation } \\
\text { Community-acquired pneumonia } \\
\text { Non-CF bronchiectasis exacerbation } \\
\text { Pharyngitis/tonsillitis }\end{array}$ & $\begin{aligned} 5 & (1-49) \\
11 & (1-29) \\
4 & (1-8) \\
3 & (1-9)\end{aligned}$ & $\begin{array}{l}9(3-190) \\
8(2-49) \\
9(6-29) \\
6(3-6)\end{array}$ \\
\hline Bloodstream* & 44 & $\begin{array}{l}\text { CLABSI_Gram-positive } \\
\text { CLABSI_Gram-negative } \\
\text { Bacteraemia—Gram-positive } \\
\text { Bacteraemia—Gram-negative }\end{array}$ & $\begin{array}{l}5(1-21) \\
7(1-27) \\
3(2-3) \\
4(1-43)\end{array}$ & $\begin{aligned} & 7(1-13) \\
11 & (2-21) \\
4 & (2-5) \\
6 & (2-31)\end{aligned}$ \\
\hline Musculoskeletal & 39 & $\begin{array}{l}\text { Acute osteomyelitis } \\
\text { Septic arthritis } \\
\text { Chronic osteomyelitis } \\
\text { Discitis } \\
\text { Pyomyositis }\end{array}$ & $\begin{array}{c}6(1-38) \\
9(1-11) \\
8(4-17) \\
7(5-14) \\
17(11-23)\end{array}$ & $\begin{array}{l}17(6-55) \\
18(4-34) \\
37(3-70) \\
23(7-48) \\
47(42-51)\end{array}$ \\
\hline Genitourinary & 30 & Urinary tract infection & $1(1-4)$ & $2(1-13)$ \\
\hline CNS & 21 & $\begin{array}{l}\text { Meningitis } \\
\text { Cerebral abscess }\end{array}$ & $\begin{array}{r}5(1-31) \\
11(8-13)\end{array}$ & $\begin{array}{c}8(1-20) \\
23(10-35)\end{array}$ \\
\hline Cardiac & 2 & Endocarditis & $8(5-10)$ & $36(35-37)$ \\
\hline Abdominopelvic & 1 & Ascending cholangitis & 22 & 48 \\
\hline
\end{tabular}

CLABSI, central line-associated bloodstream infection; CVC, central venous catheter.

which constitute a step-down from hospital in a stable patient, transfer from the ED usually represents a patient who is still on the worsening trajectory of their infection. Therefore, selecting patients in whom this is likely to be a safe alternative to hospital admission is important: clinically stable without the requirement for frequent monitoring, have an infection amenable to once or twice daily treatment and with parents not desiring admission. In our cohort, the majority of patients transferred directly from

Table 5 Adverse events and readmissions from 251 episodes of paediatric outpatient parenteral antimicrobial therapy (OPAT)

\begin{tabular}{ll}
\hline Adverse event & No. of episodes \\
\hline Line complications & $14 / 133(11 \%)$ \\
CLABSI & 3 \\
Dislodgement—resited & 3 \\
Blockage—resited & 3 \\
Blockage—-not resited & 4 \\
Paraesthesia—not resited & 1 \\
Antibiotic complications & $0 / 251(0 \%)$ \\
Anaphylaxis or immediate hypersensitivity & 0 \\
Drug side effects sufficient to change antibiotic & 0 \\
Unplanned readmissions to hospital & $11 / 251(4 \%)$ \\
Inadequate clinical improvement of infection & 3 \\
Line complications & 4 \\
New symptoms—related to OPAT & 0 \\
New symptoms—related to underlying condition & 1 \\
New symptoms—unrelated to OPAT or treated & 3 \\
infection or underlying condition, eg, viral & \\
\hline
\end{tabular}

CLABSI, central line-associated bloodstream infection. the ED for OPAT had skin and soft-tissue infection, and this group of patients has been compared at our institution with those receiving inpatient care. ${ }^{17}$ The study found that children treated via this non-admission pathway tended to be older and be less likely to have fever or periorbital cellulitis, and that all did well, and this management pathway is now subject to a randomised controlled trial. ${ }^{18}$ In our study, while overall numbers were relatively few at 42 , none of the ED patients was readmitted. Acknowledging that the patients transferred from ED are likely to have been predetermined to be at low risk for complications, good outcomes in this population are reassuring,

Antibiotic appropriateness has not previously been assessed in OPAT in children. Within this cohort, antibiotic choice was inappropriate in $6 \%$. The criteria for choice were based on our institutional guidelines where applicable, the organism if cultured, and where neither were available, the likely organisms causing a particular infection at our institution, taking into account prevailing resistance patterns. In addition, we took into account where an antibiotic was the only available choice for OPAT because of the inability to use three or four times a day dosing in this setting. All inappropriate choices were 'too broad' rather than 'too narrow', potentially resulting in an increase in antimicrobial resistance rather than risk of the child being undertreated. Higher levels of inappropriateness were attributable to incorrect dose or incorrect duration. $\mathrm{RCH}$ has dosing guidelines for all antibiotics and no reason for deviation could be found in these patients, but unlike most wards at our institution, HITH does not have a dedicated pharmacist. Duration is more subjective as there are few guidelines for the majority of infections treated in this study. Criteria for duration and intravenous oral switch were based on the limited evidence for conditions where it is available, and, where evidence was lacking, 
Table 6 Reasons for hospital readmission from 251 episodes of paediatric outpatient parenteral antimicrobial therapy (OPAT)

\begin{tabular}{|c|c|c|c|}
\hline $\begin{array}{l}\text { Patient no. } \\
\text { (episode) }\end{array}$ & OPAT reason & Readmission reason & Outcome \\
\hline 1 & $\begin{array}{l}\text { Mycobacterial CVC tunnel site infection } \\
\text { in child with short gut }\end{array}$ & Leaking CVC—admitted for CVC replacement (line complication) & Returned to HITH after 5 days \\
\hline 2 & Inguinal lymphadenitis & $\begin{array}{l}\text { Increasing lymph node size—admitted for USS followed by incision } \\
\text { and drainage (inadequate improvement) }\end{array}$ & Returned to HITH after 2 days \\
\hline 3 & $\begin{array}{l}\text { CVC infection (Bacillus cereus) in child } \\
\text { with haemophilia }\end{array}$ & $\begin{array}{l}\text { Ongoing positive CVC blood cultures despite appropriate antibiotics- } \\
\text { admitted for CVC removal (inadequate improvement) }\end{array}$ & $\begin{array}{l}\text { No further OPAT—discharged off } \\
\text { antibiotics }\end{array}$ \\
\hline 4 & Vertebral osteomyelitis/discitis & $\begin{array}{l}\text { PICC line dislodged—admitted for PICC line replacement (line } \\
\text { complication) }\end{array}$ & Returned to HITH after 5 days \\
\hline 5 (1st) & Postsurgical deep wound infection & $\begin{array}{l}\text { Large serous discharge from wound-admitted for observation } \\
\text { (inadequate improvement) }\end{array}$ & Returned to HITH after 3 days \\
\hline $5(2 n d)$ & Postsurgical deep wound infection & $\begin{array}{l}\text { Pleuritic chest pain—admitted for investigation of pulmonary embolism } \\
\text { (negative); diagnosed likely viral (not OPAT-related) }\end{array}$ & Returned to HITH after 2 days \\
\hline 6 (1st) & Discitis & $\begin{array}{l}\text { Fever-admitted for repeat MRI (improved); hand, foot and mouth } \\
\text { lesions developed the next day (not OPAT-related) }\end{array}$ & Returned to HITH after 2 days \\
\hline 6 (2nd) & Discitis & $\begin{array}{l}\text { Fever and blocked line-admitted for observation and CVC removal, } \\
\text { coryzal symptoms the next day (line complication) }\end{array}$ & $\begin{array}{l}\text { No further OPAT—discharged on oral } \\
\text { antibiotics }\end{array}$ \\
\hline 7 & Discitis & $\begin{array}{l}\text { Night sweats—admitted for investigation; cultures negative but } \\
\text { replaced CVC (line complication) }\end{array}$ & Returned to HITH after 3 days \\
\hline 8 & $\begin{array}{l}\text { CVC infection (Escherichia coli) in child } \\
\text { with short gut }\end{array}$ & $\begin{array}{l}\text { Non-specifically unwell but afebrile on final day of antibiotics- } \\
\text { admitted for observation; diagnosed likely viral (not OPAT-related) }\end{array}$ & $\begin{array}{l}\text { No further OPAT-discharged off } \\
\text { antibiotics }\end{array}$ \\
\hline 9 & $\begin{array}{l}\text { CVC infection (Staphylococcus aureus) } \\
\text { in child with Ewing's sarcoma }\end{array}$ & $\begin{array}{l}\text { Bleeding from port site and low platelets—admitted for nitrous gas to } \\
\text { access port and platelet transfusion (related to underlying condition) }\end{array}$ & Returned to HITH after 6 hours \\
\hline
\end{tabular}

HITH, hospital-in-the-home; CVC, central venous catheter PICC, peripherally inserted central catheter.

'usual' accepted practice based on the infection itself and clinical improvement. While practice differs between institutions and countries, there is reasonable consensus at our institution and we erred on the side of generosity. However, there were clear instances of failure to switch/stop with clinical improvement where long intravenous antibiotic durations are not considered usual practice. Input from Infectious Diseases physicians has previously been shown to be helpful in stewarding antibiotic choice and duration. ${ }^{14}{ }^{19}$ At our institution, the antimicrobial stewardship committee has global supervision of antimicrobial use and education, but lacks resources to provide individual patient care either on an inpatient or outpatient basis, and antibiotic choices are made by the referring team with support from Infectious Diseases on request. However, the risk of patients receiving OPAT being 'out of sight, out of mind' means that it is arguably of even greater importance to have stewardship of their antimicrobial treatment.

OPAT with a HITH service was also shown to be costeffective, with an estimated cost saving of AU\$1.82 million in 1 year. While the OPAT service was costed accurately, the cost of an inpatient bed varies somewhat depending on the condition. OPAT is a medical intervention, so we used the average cost of a general medical bed using the same approach of salaries, operational and patient-related costs. The cost saving is likely to be a conservative estimate as the costs of surgical and medical specialty inpatient beds are even higher. This is very appealing with ever-increasing healthcare costs, particularly as it does not appear to come at the expense of efficacy or safety, and a systematic review has concluded that hospital care at home is more cost-effective than inpatient care. ${ }^{4}$ However, a comparative study with inpatient care is needed to truly assess this as there may be hidden costs such as longer lengths of stay under HITH that may offset this, and costs attributable to individual infections may be different from the average cost difference used. The cost benefits to families would also be of interest as an area for future study. While this cost-effectiveness comparison relates specifically to the Australian healthcare system with government funding, it is also applicable to systems funded in different ways, with the savings transferrable to individual institutions, patients or insurance companies.

The strengths of this study are that it is the largest one of its kind in children to date and that the information was collected prospectively. This study did not directly compare outcomes of OPAT with inpatient antimicrobial therapy, and these groups may be different. Previous studies investigating specific conditions at our institution have not shown a difference between inpatient and outpatient outcomes but only a randomised study would truly answer this. ${ }^{20}$ This study identified a number of areas for improvement in our OPAT service and has resulted in several outcomes: (1) a specific RCH OPAT guideline has been written; (2) there is Infectious Diseases oversight of all HITH patients, and although the ultimate decision remains with the referring teams, there is greater individualised input in antibiotic use; (3) the HITH registrar has been designated as responsible for following results of therapeutic drug monitoring and adjusting doses appropriately; and (4) a proposal for a dedicated pharmacist has been made.

\section{CONCLUSIONS}

In our cohort of patients, OPAT appears to be safe (few adverse events), efficacious (low rate of unplanned readmissions) and cost-effective (cheaper than an equivalent inpatient bed stay). There is room for improvement in documentation, drug monitoring and appropriateness and the development and implementation of an OPAT-specific guideline and increased oversight of antimicrobial use will be important.

Acknowledgements The authors acknowledge the work of the clinical staff providing care for these patients.

Contributors $\mathrm{KAH}$ drafted the manuscript, developed the project, contributed to and compiled data, edited the draft and approved the final manuscript. JH, LFI, BS, DG, ML, MS and C-MR developed the project, contributed to and compiled data, reviewed and edited the draft and approved the final manuscript. PAB conceived 
and designed the project, reviewed the data, reviewed and edited the draft and approved the final manuscript.

Funding During this work, PAB was in receipt of grants from the Victorian Department of Health Quality and Efficiency grants, the Murdoch Children's Research Institute and The Royal Children's Hospital Foundation, Melbourne.

Competing interests None declared.

Ethics approval Royal Children's Hospital Human Research Ethics Committee.

Provenance and peer review Not commissioned; externally peer reviewed.

\section{REFERENCES}

1 Patel S, Abrahamson E, Goldring S, et al. Good practice recommendations for paediatric outpatient parenteral antibiotic therapy ( $p$-OPAT) in the UK: a consensus statement. J Antimicrob Chemother 2015;70:360-73.

2 Orme LM, Babl FE, Barnes C, et al. Outpatient versus inpatient IV antibiotic management for pediatric oncology patients with low risk febrile neutropenia: a randomised trial. Pediatr Blood Cancer 2014;61:1427-33.

3 Goodfellow AF, Wai AO, Frighetto L, et al. Quality-of-life assessment in an outpatient parenteral antibiotic program. Ann Pharmacother 2002;36:1851-5.

4 Shepperd S, Doll H, Angus RM, et al. Avoiding hospital admission through provision of hospital care at home: a systematic review and meta-analysis of individual patient data. CMAJ 2009;180:175-82.

5 Caplan GA, Sulaiman NS, Mangin DA, et al. A meta-analysis of "hospital in the home". Med J Aust 2012;197:512-19.

6 Tice $A D$, Rehm SJ, Dalovisio JR, et al. Practice guidelines for outpatient parenteral antimicrobial therapy. IDSA guidelines. Clin Infect Dis 2004;38:1651-72.

7 Moore D, Bortolussi R. Home intravenous therapy: Accessibility for Canadian children and youth. Paediatr Child Health 2011;16:105-14.

8 Sartain SA, Maxwell MJ, Todd PJ, et al. Users' views on hospital and home care for acute illness in childhood. Health Soc Care Community 2001:9:108-17.
9 Madigan T, Banerjee R. Characteristics and outcomes of outpatient parenteral antimicrobial therapy at an academic children's hospital. Pediatr Infect Dis 2013;32:346-9.

10 Maraqa NF, Rathore MH. Pediatric outpatient parenteral antimicrobial therapy: an update. Adv Pediatr 2010;57:219-45.

11 Manji A, Beyene J, Dupuis LL, et al. Outpatient and oral antibiotic management of low-risk febrile neutropenia are effective in children-a systematic review of prospective trials. Support Care Cancer 2012:20:1135-45.

12 Van Winkle P, Whiffen T, Liu IL. Experience using peripherally inserted central venous catheters for outpatient parenteral antibiotic therapy in children at a community hospital. Pediatr Infect Dis J 2008;27:1069-72.

13 Gomez M, Maraqa N, Alvarez A, et al. Complications of outpatient parenteral antibiotic therapy in childhood. Pediatr Infect Dis J 2001;20:541-3.

14 Maraqa NF, Gomez MM, Rathore MH. Outpatient parenteral antimicrobial therapy in osteoarticular infections in children. J Pediatr Orthop 2002;22: 506-10.

15 Rucker RW, Harrison GM. Outpatient intravenous medications in the management of cystic fibrosis. Pediatrics 1974;54:358-60.

16 Collaco JM, Green DM, Cutting GR, et al. Location and duration of treatment of cystic fibrosis respiratory exacerbations do not affect outcomes. Am J Respir Crit Care Med 2010;182:1137-43.

17 Ibrahim LF, Hopper SM, Babl FE, et al. Who can safely have antibiotics at home? A prospective observational study in children with moderate/severe cellulitis. Pediatr Infect Dis J 2016:35:269-74.

18 Ibrahim LF, Babl FE, Orsini F, et al. Cellulitis: home or inpatient in Children from the Emergency Department (CHOICE): protocol for a randomised controlled trial. BMJ Open 2016;6:e009606.

19 Osowicki J, Gwee A, Noronha J, et al. The impact of an infectious diseases consultation on antimicrobial prescribing. Pediatr Infect Dis J 2014;33: 669-71.

20 Hopper SM, Ibrahim LF, Babl FE, et al. A comparison of treatment at home or in hospital for moderate/severe cellulitis in children. Arch Dis Child 2014;99: A246-A7. 